\title{
A decade of human ARTs: On the likenesses of being a gamete, embryo, or organ
}

\author{
David F. Albertini ${ }^{1}$
}

Published online: 8 December 2019

(C) Springer Science+Business Media, LLC, part of Springer Nature 2019

\begin{abstract}
"Most scientific problems are far better understood by studying their history than their logic."

Ernst Mayer, The Growth of Biological Thought. Harvard University Press, 1982.
\end{abstract}

Ten years into serving as your Editor has provided human ART practitioners insights hardly imaginable in 2009 when the ASRM joined forces with Springer to make JARG a sentinel for our readership and field of reproductive medicine and biology. Who could have predicted such changes in the technological landscape of contemporary research generally, or even more to the point that the inner workings of gametes or embryos of so many animal forms would arrive on public display. What matters now is that we learn from the way the ever expanding array of technology platforms have influenced not only our clinical practice but the ways in which science interfaces with a society increasingly concerned with the power and potential uses now firmly in the hands of scientists and clinicians alike. It is with the spirit of balance, discretion, and moderation that JARG is poised to maintain a dialogue between patients, stakeholders, discoverers, and physicians as we move into the next decade of human ARTS.

Retrofitting the logic of contemporary ARTs within a historical purview encompassing the roots and foundations of reproductive biology is anything but a straightforward exercise. With celebrations laced by an epidemic of selfaggrandizement recognizing the 40 years of medical progress since the birth of the first IVF baby, human ARTs assumed a rightful position in the biomedical enterprise as much more than the original pathway to treating blocked fallopian tubes of years gone by. It is indisputable that bringing the hidden treasures of our viviparous origins into the limelight of human perception (and manipulations), coupled with rapidly

David F. Albertini

eicjarg@gmail.com

1 Center for Human Reproduction, New York, NY, USA advancing analyses proffered through the various $O M E S$ or OMICS of today, our embryonic heritage now straddles a fine line between science and society.

The year 2019 will be long remembered as that of a nexus for moving well-intentioned treatments for infertility into the realm of gene editing. Consider for a moment Professor Doudna's sobering reminder as to how science will need to proceed in the CRISPR era given the birth earlier this year of the first two children whose germline now bears the signature of human intervention (https://science.sciencemag.org/ content/366/6467/777). And like it or not, 40 years of "progress" in human ARTs enabled this and other ongoing efforts down a slippery slope not likely to gain traction anytime soon despite calls for moratoria of ill-defined parameters. Just down the road a bit, and not having gone unnoticed relative to efforts several ago to extend the culture of human embryos proximal to the so-called 14-day rule, the publication of reports has arrived extending well beyond the plethora of "organoid" papers suiting the needs and aspirations of disease hunters and gatherers of various ilks.

Call it the decade of the organoid, organ-like entities propagated from stem cells to mimic the structure and function of the tissue constructs mediating bodily homeostasis, or more fitting perhaps the decade that gave rise to the likenesses of various cell types near and dear to our specialty and beyond. We have witnessed the propagation of sperm and eggs from stem cells, at least in the exquisitely tractable and manipulatable mouse model. And apparently we are on the verge of taking our familiarity with early human development to and through the processes of implantation and gastrulation. To wit, claims of success with the extended culture of nonhuman primate embryos to the stage of forming germ layers and extraembryonic membranes have been realized. In no small way has this field of contemporary research been spawned by the clinical drive to extend culture of human embryos over the past decade, ostensibly for purposes of gaining improvements in our ability to select the best of the available embryos. 
Back to the matter of organoids. Seems that the business of making organoids to model organ development and disease (and of course large scale drug screening opportunities) has melded the wonderful world of regenerative medicine with bioengineering to an astonishing degree. And this nexus of disciplines appears to have slowly drifted rearward in a developmental sense to afford the community of reproductive medicine and biology enthusiasts the opportunity to recreate (careful) their own version of a Brave New World. Take for example the brilliant studies from the University of Michigan group several months ago.

Zheng and their colleagues deployed a sophisticated microfluidics system to fashion advanced stages of what appears to be embryogenesis using stem cells exposed to a pattern of growth factors suspected to be involved from in vivo studies of mouse development [1]. Clever indeed, and a sign of things yet to come. Any doubts you may have about how tuned in the public is to these advances can be set to rest by a glimpse of the persuasive and powerful testimony the nonfake news journalists are sharing with your friends, families and clients (https://apple.news/Attleyre1RuuKqvA2o0niLw). And there is no shortage of "lookalikes" on the horizon certain to raise the sensitivities of investors in truth or finance given the continuing tradition of leading laboratories to reveal the deepest secrets of blastoids made from stem cells [2].

Even the top-ranked journals gain widespread publicity kudos when studies like the one cited above are linked to the deepening of our understanding of a diseases' origin and possible pathways to a cure or elimination [1]. Such was the case constructed in a commentary of this work with specific regard for how the devastating consequences of miscarriage may acquire a better understanding now that models for this critical juncture in early human development have entered the factory-like level of production-and hence availability for science to explore and remediate under controlled conditions [3].
Progress has been extraordinary in clinical ARTs over the past 10 years. Whether the introduction of so many accoutrements (referred to as add-ons by some) will in the end prove to be of measurable value to overall success rates remains both a matter of inquiry and discourse. Prevailing attitudes among the reigning driving forces within the ART community have enabled the adoption of many procedures and protocols without strict adherence to guidelines typically used in other medical disciplines. What this portends is yet another decade of advance likely to create opportunities appearing on the surface to improve diagnostic and treatment strategies over what has been realized since 2009. If there is a logical basis for how human ARTs should proceed in the future, then perhaps a close examination of our recent history would be a worthwhile endeavour-at least before the next round of gene edited babies arrive.

In closing with this our final issue for 2019, we would like to acknowledge the contributions of authors, reviewers, and editorial board members who have been the substance of our own "interactome" for a fruitful and productive year. Best wishes to all for a happy and healthy holiday season.

\section{References}

1. Zheng Y, Xue X, Shao Y, Wang S, Esfahani SN, Li Z, et al. Controlled modelling of human epiblast and amnion development using stem cells. Nature. 2019;573:421-5.

2. Li R, Zhong C, Yu Y, Liu H, Sakurai M, Yu L, et al. Generation of blastocyst-like structures from mouse embryonic and adult cell cultures. Cell. 2019;179:687-702.

3. Clark A. Human embryo implantation modelled in microfluidic channels. Nature. 2019;573:350-1.

Publisher's note Springer Nature remains neutral with regard to jurisdictional claims in published maps and institutional affiliations. 